\title{
THE INFLUENCE OF ENERGY EFFICIENCY ON OTHER RESOURCES USE: AN INPUT-OUTPUT PERSPECTIVE
}

\author{
Jaume Freire-González ${ }^{\text {a,1 }}$ \\ David Font Vivanco ${ }^{b}$
}

\author{
${ }^{a}$ Department of Economics, Harvard University, Cambridge, Massachusetts 02138, United States. \\ ${ }^{\mathrm{b}}$ Center for Industrial Ecology, School of Forestry and Environmental Studies, Yale University, New \\ Haven, Connecticut 06511, United States.
}

\begin{abstract}
Energy efficiency improvements reduce the costs of energy services, and under some circumstances, increase the available income. This generates an additional increase of consumption of goods and services that need additional energy to be produced, distributed and consumed. This effect is known as indirect rebound effect. However, beyond this additional increase of global energy consumption, there is also a variation of the use of other resources for the same reason. So, after an energy efficiency improvement there is an indirect effect on other resources use that have to be considered. This is effect, named as direct and indirect cross rebound effect is not considered by academia nor policy-making when designing and implementing energy policies. This research shows a methodology to estimate this effect, and provides estimates for Spain. Results show that an energy efficiency could increase the use of minerals and water, while reducing the use of energy, fossil fuels and metal ores. These reductions, however, are lower than the expected ones from an input-output perspective, leading to positive direct and indirect cross rebound effects.
\end{abstract}

Keywords: energy efficiency, cross rebound effect, resource use, input-output.

\footnotetext{
${ }^{1}$ Corresponding author.

E-mail addresses: jfreire@ fas.harvard.edu, jaumefreire@ hotmail.com.
} 


\section{Introduction}

Energy efficiency improvements are often promoted to reduce energy consumption from different economic agents, such as households, industries and governments. Such improvements are applied to various areas, such as lighting, heating, cooling, industrial processes, and other areas that require energy. It is one of the most widespread policies to deal with energy dependency and environmental problems in most countries (IEA 2015). Increasing concerns on climate change have also fostered these policies in order to reduce global carbon emissions and tackle global warming.

There is, however, a known controversy among energy economists. Energy efficiency improvements can be totally or partially offset by the so-called rebound effect. This effect has been widely studied for energy uses (Brookes 1979; Khazzoom 1980; Saunders 1992; Greening et al. 2000; Sorrell 2007; Freire-González 2010). The intuition behind this effect is that an increase in the efficiency of using a given resource (e.g. energy) reduces the unitary cost of the service it provides (e.g. heating), from which follows an increase in its demand and the consequent offsetting of some or all of the initial expected savings. This is generally known as the direct rebound effect (Greening et al., 2000). Moreover, there is also an increase of the available income that can lead to additional final demand for other products and services, which in turn may require of such resource during their life cycle (from extraction to final disposal). This is commonly known as the indirect rebound effect (ibid.). Both effects have been extensively analysed for energy uses, but less so for other resources (Font Vivanco and van der Voet, 2014). This is due to several reasons: the energy crisis in the 1970s and its importance in economic systems; the importance of energy in GHG emissions and global warming; energy dependence and geostrategic reasons, etc. A key question is thus how energy efficiency and its associated rebound effects affects the global use of resources other than energy. A better understanding of this question can help to anticipate unforeseen consequences, identify tradeoffs and co-benefits and find optimal solutions between environmental problems.

Empirical evidence shows that the indirect rebound effect is a key driver of the overall rebound effect in many cases (Chitnis et al., 2013, 2014; Font Vivanco et al., 2014; Zhang et al., 2017), and consequently an important body of research has focused on its study (Druckman et al., 2011; Sorrell, 2007). Research on the indirect rebound effect shows that energy efficiency 
improvements generally lead to monetary savings that can be re-spent on other goods and services, in turn increasing the overall energy consumption (Druckman et al. 2011; FreireGonzález 2011, Chitnis et al. 2014). In some cases, the indirect effect can even play a major role in superseding any energy savings (Druckman et al., 2011; Font Vivanco et al., 2015; Zhang et al., 2017), a case commonly known as 'backfire effect' (Saunders, 2000). Some authors argue that, because goods and services are associated with multiple environmental pressures during their life cycle, such as waste and various air emissions, the indirect rebound effect can be expressed through various metrics (Alfredsson, 2004; Font Vivanco et al., 2014; Takase et al., 2005; Thiesen et al., 2008). Such a broader interpretation has sometimes been framed within the 'environmental rebound effect' (ERE) concept, which generalises the traditional energy rebound effect to encompass efficiency changes and indicators of interest that go beyond energy and energy-related emissions to a wide range of environmental issues (Font Vivanco et al., 2016; Goedkoop et al., 1999; Murray, 2013). Nevertheless, the study of rebound effects in the context of multiple environmental pressures, defined here as 'cross rebound effects', is in its infancy, with only a handful of empirical estimates available. Further research can provide a better understanding on the underlying reasons and the implications of such combined effects, including trade-offs, co-benefits and the possibility of backfire.

This research aims at setting up a framework to empirically assess the impact of energy efficiency improvements in households and associated rebound effects on non-energy resources. To this end, we develop the concept of the direct and indirect cross rebound effect, and apply it to estimate the impact of energy efficiency on the use of energy, fossil fuels, metal ores, non-metallic minerals and water for the case of Spain. Section 2 describes the context and some definitions from the literature. Section 3 shows the proposed methodology to assess direct and indirect cross rebound effect at the household level, and section 4 describes the data for the case study. Section 5 provides estimates of the direct and indirect cross rebound effects and discussion, and section 6 concludes.

\section{Context}

Energy services -like, e.g., thermal conditions of houses- are what final consumers actually demand, rather than energy itself. Their production require energy, but also capital, labour and the expert management of households, firms and governments (Sorrell 2007). It can be assumed 
that energy efficiency improvements reduce the marginal cost of the provision of energy services, and so various economic agents react to this reduction by increasing the demand of these services, and consequently the demand of energy, if energy services are considered normal goods. This increased consumption of energy services are expected to offset part of the reduction in energy consumption initially predicted. In this context, Becker's (1965) household production framework is useful to understand the demand of services provided by resources like energy. However, additional effects arise from an energy efficiency improvement.

According to the traditional literature on the rebound effect, three main categories of rebound effects can be considered: direct, indirect and economy-wide rebound effect (Greening and Green, 2000), although other types can also been found in literature. In the context of energy rebound effects, direct rebound effect refers to the increase of the demand of the own energy service that has improved its efficiency. Indirect rebound effect refers to changes on the demand of other goods and services, and their associated life cycle energy requirements, from the monetary savings derived from the cost reductions triggered by the more efficient systems. Economy-wide effects imply changes in prices, supplies and demands through the overall economic system. Increases in the overall economic productivity are usually also included in this typology, although they have other implications.

Some indirect rebound effect literature has found the link between the energy efficiency improvements and the overall energy consumption through the so-called 're-spending' effect (Druckman et al. 2011; Freire-González 2011; Thomas and Azevedo 2013a, 2013b; FreireGonzález et al. 2017). This is a straightforward way to reallocate monetary savings from efficiency improvements and obtain the additional increase of energy needed to produce the goods and services demanded. A common methodology used in some of these studies have been using a re-spending model linked with an extended (energy) input-output model. In this article, we develop a methodological framework that generalises this method, not only to energy consumption, but also to other resources. It allows to assess the consumption increase/decrease of other resources following an energy efficiency variation. We will also apply it to the specific case of Spain for some specific resources.

\section{Methodology}


The methodology described in this section is inspired by different academic backgrounds, but mostly from the direct and indirect rebound literature for energy efficiency. Some adaptations, however, are needed for its generalisation to other resources. Given that an improvement in energy efficiency has effects on the size and allocation of the final consumption, it has effects not only on indirect energy usage, but also on the indirect use of other resources. This consideration looks intuitive from a life cycle assessment perspective, where each unit of final consumption is associated with resource use over all its life cycle, including the extraction, production, use and waste management stages. So, how does the indirect rebound effect from an energy efficiency improvement affect the use of other natural resources beyond energy? To address this question, it is necessary a broad perspective and a thorough analysis of the indirect effects of energy efficiency improvements.

Particularly, Freire-González (2011) developed a framework for direct and indirect energy use from energy efficiency improvements in households that can be adapted and generalized for other resources. Following this framework, three different steps are combined in this research, each using different methods. First, the use of econometrics and energy demand models to obtain the direct rebound effect from price-elasticity of demand for energy; second, the use of a re-spending model to allocate households' monetary savings from energy efficiency to other goods and services, considering households' budgets, and according to different scenarios; and third, an estimation of the direct plus indirect use of other resources from the new consumption pattern through the use of an environmental extended input-output framework (Miller and Blair 2009).

\subsection{Direct energy rebound effect}

The direct rebound effect for energy uses is the most analysed issue in both the theoretical and empirical rebound literature. There are well-established standard methods to obtain the direct rebound effect form energy services, and empirical evidence is sound (Sorrell 2007). The most common way to estimate the direct rebound effect is through the use of elasticities of demand. The direct rebound effect can be defined as (Khazzoom 1980; Berkhout et al. 2000; Dimitropoulos and Sorrell 2006; Sorrell 2007):

$$
\vartheta_{\alpha}\left(x_{E}\right)=\vartheta_{\alpha}\left(S_{E}\right)-1
$$


where $\vartheta_{\alpha}\left(x_{E}\right)$ is the efficiency elasticity of the demand for energy and $\vartheta_{\alpha}\left(S_{E}\right)$ is energy efficiency elasticity of the demand for useful work for an energy service. When the energy efficiency elasticity of the demand for useful work for an energy service is equal to zero, there is no direct rebound effect. When $\vartheta_{\alpha}\left(S_{E}\right)>0$, so $\left|\vartheta_{\alpha}\left(x_{E}\right)\right|<1$ there is a positive direct rebound effect. Finally, when $\vartheta_{\alpha}\left(S_{E}\right)>1$, so the demand is elastic, would produce "backfire" (Saunders, 1992).

However, under certain assumptions, the rebound effect can also be obtained from the own price-elasticity of the demand for energy. Under this approach, the following equation can be obtained (Khazzoom 1980; Binswanger 2001; Berkhout et al. 2000; Dimitropoulos and Sorrell 2006; Sorrell 2007):

$$
\vartheta_{\alpha}\left(x_{E}\right)=-\vartheta_{P E}\left(x_{E}\right)-1
$$

where $\vartheta_{P E}\left(x_{E}\right)$ is the own price elasticity of the demand for energy. This expression is based on two main assumptions. The first one is that responses to decreasing energy prices are the same than responses to energy efficiency -this is known as the 'symmetry assumption'-. The second one, known as 'exogeneity assumption', states that energy efficiency is not affected by changes in energy prices.

\subsection{The re-spending model}

The re-spending model is the link between the energy efficiency improvement and the resource input-output model. We will model it following Freire-González (2011), Druckman et al. (2011) and Thomas and Azevedo (2013a,b). The increase of resource use due to the respending effect can be defined as:

$$
\Delta r=\sum_{i=1}^{n} u_{i} \Delta x_{i} p_{i}+u_{s} \Delta s
$$

where $u_{i}$ is an operator that turns variations of final demand from monetary savings into variations of resource use, $x_{i} p_{i}$ is the demand on sector $i$ (composed of quantity $[x]$ and price $[p]), u_{s}$ is an operator that turns variations of savings into variations of resource use, and $s$ are 
savings. For household expenditures $u_{i}$ is represented in this modelling framework through $R(I-A)^{-1}$ from the input-output model of equation (10).

The households' budget equilibrium can be defined as follows:

$$
y=x_{E} p_{E}+\sum_{i=1}^{n} x_{i}^{\prime} p_{i}+s
$$

Or:

$$
\Delta y=\Delta x_{E} p_{E}+\sum_{i=1}^{n} \Delta x_{i}^{\prime} p_{i}+\Delta s
$$

where $y$ is the household income or the total budget, $x_{E}$ is the amount of energy, $p_{E}$ is the price of energy, $x_{i}^{\prime}$ are other goods and services different from energy supply, $p_{i}$ is the price of the good or service $i$, and $s$ are the monetary savings.

The marginal propensity to save $(p)$ can be defined as $p=\frac{\Delta s}{\Delta y}$. From this equation: $\Delta s=r \Delta y$. If this equation is inserted into equation (8) and some arrangements are made:

$$
(1-p) \Delta y=\Delta x_{E} p_{E}+\sum_{i=1}^{n} \Delta x_{i}^{\prime} p_{i}
$$

The income elasticity of expenses can also be defined as:

$$
\vartheta_{y}\left(x_{i}\right)=\frac{\Delta x_{i} p_{i}}{\Delta y} \frac{y}{x_{i} p_{i}}
$$

\subsection{Resource input-output model}

In order to obtain the total resource use under several re-spending scenarios, a generalized input-output model can be built. This is a specific case of an environmental extended inputoutput model for different resources used in the production process (Miller and Blair 2009). This model allows to obtain the total resource use -both direct resource use and their corresponding upstream requirements- from different final demand or final consumption patterns. We can start from the expression: 


$$
r=R x
$$

where $r$ is a vector of resource use by different economic sectors, $R$ is a matrix of resource intensities or direct use coefficients of resources, and $x$ is a vector of sectoral output. On the other side, the traditional Leontief model can be expressed as (Leontief 1941):

$$
x=(I-A)^{-1} f
$$

where $(I-A)^{-1}$ is the inverse matrix of the Leontief production model, and $f$ is the final demand vector for economic sectors. If equation (4) is inserted in equation (3), the next expression can be obtained:

$$
r=R(I-A)^{-1} f
$$

This equation provides the total use for a set of resources from a given final demand. This formulation can also be expressed in terms of changes in final demand, which would yield the corresponding changes in total resource use.

\subsection{Direct and indirect cross rebound effect}

A new concept can be defined that relates the change in energy efficiency with the change in resource use. The direct and indirect cross rebound effect (DICRE) is an increase in other resource use after an energy efficiency improvement, due to the increase of available income. This effect can be mathematically defined as follows:

$$
D I C R E=\frac{\text { Calculated resource savings }- \text { Real resource savings }}{\text { Calculated resource savings }}
$$

The calculated resource savings - without rebound- can be named as $H$, and the additional resource use given by the rebound and re-spending effect $R e$. This concept is somewhat different than the rebound effect as traditionally defined, although it has the same logic. The main difference consists on the understanding of the 'calculated resource savings' for other 
resources. One can assume that, after an energy efficiency improvement, there are no expected savings of other resource use. However, from a global perspective, considering indirect effects, we can assume that, initially, some degree of reduction is expected as less income is allocated to the energy sector, generating less global resource use. These effects that can be understood and accounted using input-output and/or life-cycle assessment methods (Font Vivanco et al., 2016). See section 3.2 for a detail of the input-output model proposed in this research.

From this perspective, the direct and indirect rebound effect can be formulated as:

$$
D I C R E=\frac{\Delta H-(\Delta H-\Delta R e)}{\Delta H}=\frac{\Delta R e}{\Delta H}
$$

Substituting (7) in (6), using (3) and making arrangements, a new formula for rebound effect can be obtained:

$$
D I C R E=\frac{\Delta R e}{\Delta H}=\frac{1}{\Delta H}\left[\frac{(1-r) \Delta y-\Delta x_{E} p_{E}}{\sum_{i=1}^{n} \vartheta_{y}\left(x_{i}\right) x_{i} p_{i}}\right] \sum_{i=1}^{n} u_{i} \vartheta_{y}\left(x_{i}\right) x_{i} p_{i}+u_{s} r \Delta y
$$

This formula provides the direct and indirect cross rebound effect for energy efficiency improvements in households. In order to allow for different re-spending scenarios, the next equation will be used, from Freire-González (2011): ${ }^{2}$

$$
\sum_{i=1}^{n} x_{i}^{\prime} p_{i}=y-\left[1+\left(-\vartheta_{P E}\left(x_{E}\right)-1\right) \frac{\Delta \varepsilon}{\varepsilon}\right] x_{E} p_{E}-s
$$

where $\frac{\Delta \varepsilon}{\varepsilon}$ is the increase in energy efficiency This equation estimates the direct and indirect cross rebound effect of energy efficiency improvements under different re-spending scenarios, using the own price elasticity of the demand for energy. For illustrative purposes, the assumption that there are no monetary savings has been imposed for equation (14).

As shown in Freire-González (2011), different potential re-spending scenarios are possible using equation (14). In order to simplify the analysis, a proportional re-spending scenario has been assessed in this study. In this scenario, monetary savings are reallocated according to the

\footnotetext{
${ }^{2}$ See that study for a detail on the steps followed to obtain it.
} 
share of each good or service on the total households' budget, i.e., the new income generated by an energy efficiency improvement is spent in the same way that before. Input-output data contains information on households' final demand. The proportional re-spending scenario is formulated as:

$$
x_{i}^{P} p_{i}=x_{i} p_{i}\left[1+\frac{x_{E} p_{E}\left(1-\left[1+\left(-\vartheta_{P E}\left(x_{E}\right)-1\right) \frac{\Delta \varepsilon}{\varepsilon}\right]\right)}{\sum_{i=1}^{n} x_{i} p_{i}}\right]
$$

Equation (15) defines the new households' expenditure on different goods and services using an estimation of the direct rebound effect (own price energy elasticity) and considering a proportional scenario for new income allocation. There are also other possibilities in reallocating new income like the use of income elasticities or other more sophisticated econometric approaches (like the estimation of Almost Ideal Demand Systems). These approaches, however, require comprehensive data on all goods and services detailed in the input-output system, which are not currently available. Further research can improve this aspect.

\section{Data}

\subsection{Direct rebound effect}

The first step is to provide estimates of the direct rebound effect, by using own price elasticities of the demand for energy for residential uses. In order to account for this effect before reallocating the new available income, it is necessary to obtain estimations for it. A straightforward way shown in literature to obtain the direct rebound effect is by using own price elasticities of the demand for the relevant energy service. As shown in previous sections, literature states that, under some circumstances, they can be used to obtain a proxy of the direct rebound effect, by assuming that an efficiency improvement equals to a reduction in marginal cost of the relevant service. However, despite this is a useful and easy way to estimate them, we have to be aware that this approach tends to overestimate rebound effect (Sorrell 2007). 
A commonly used approach to estimate price elasticities is to specify a demand model for residential energy uses. The estimation of the model can be conducted using a logarithmic functional form provides elasticities of the estimated parameters:

$$
\ln E=\beta_{0}+\beta_{1} \ln P_{E}+\beta_{2} \ln P_{i \prime}+\beta_{3} \ln Y+\beta_{4} \ln C+\beta_{5} \ln Z+u
$$

This is a general econometric model where energy demand $E$ depends on the price of energy $P_{E}$, the prices of other goods and services $P_{i \prime}$, the disposable income $Y$, weather conditions $C$ and other factors $Z$. In this specification, the value of $\beta_{1}$ provides the own price elasticity of demand for energy, and then, a proxy of the direct rebound effect for that specific energy source or service. Estimations of the own price elasticities of the demand for residential energy uses can be found in literature for different countries/regions. There are a several surveys and other research studies that estimate elasticities using different methods and data, and some interesting and comprehensive literature reviews (e.g.: Atkinson et al. 1995; Brons et al. 2008; Suganthi et al. 2012; etc.).

For illustrative purposes we have conducted a sensitivity analysis using a range between 0 and -1 for residential demand. We can then assume that the direct rebound effect for domestic uses would range between $0 \%-100 \%$. That means that an efficiency improvement expected to reduce 100 units of energy consumption in households would finally reduce it between 100 0 . In any case, whatever the elasticity value is finally chosen for analytical purposes, the final use of energy as a result of direct rebound effect is not expected to increase from the direct rebound effect perspective, since most studies show that energy demand for most uses in industrialized countries is inelastic, so minor than 1 .

\subsection{Environmentally extended input-output tables}

The empirical analysis has been carried out using the Exiobase v.2 database (Tukker et al., 2013; Wood et al., 2015). This dataset offers an extended multiregional input-output framework for 2007, including additional accounts on different resources linked to the industries and final consumption. The Spanish input-output table and its different satellite accounts for the different resources has been isolated. These additional accounts on different 
resources use are for: energy (total energy carrier use), fossil fuels, metal ores, non-metallic minerals and water (green and blue). This input-output framework contains a detail of 163 industries and 48 countries/regions.

\section{Results and discussion}

This section contains the development of an application of the described method for estimating the effects of energy efficiency improvements in households in Spain for different resources. Specifically, we have computed the total use of fossil fuels, water, metal ores, non-metallic minerals and energy use, after an energy efficiency improvement in households in the Spanish economy and the DICRE for all these resources in Spain.

Five generalized input-output models have been built following the methodology shown in section 3.2, one per each natural resource. Then the cross rebound effect has been estimated in each of them under different assumptions on energy efficiency improvements in households and using different own price elasticities of energy. The results in terms of total variation of different resources use from the simulations can be seen in figures 1-5.

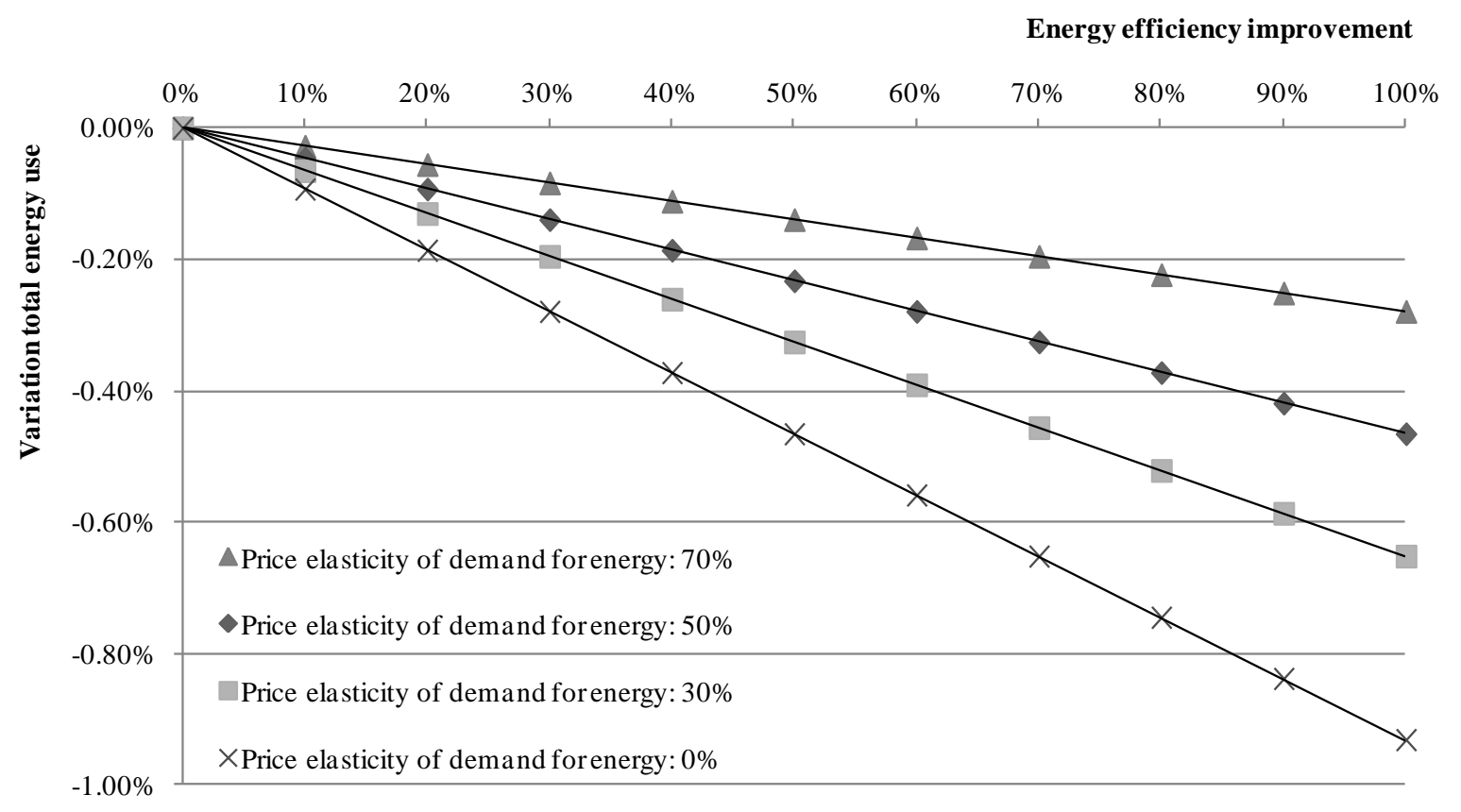

Figure 1 Energy variation after an energy efficiency improvement in households in Spain under different scenarios. 
Energy efficiency improvement

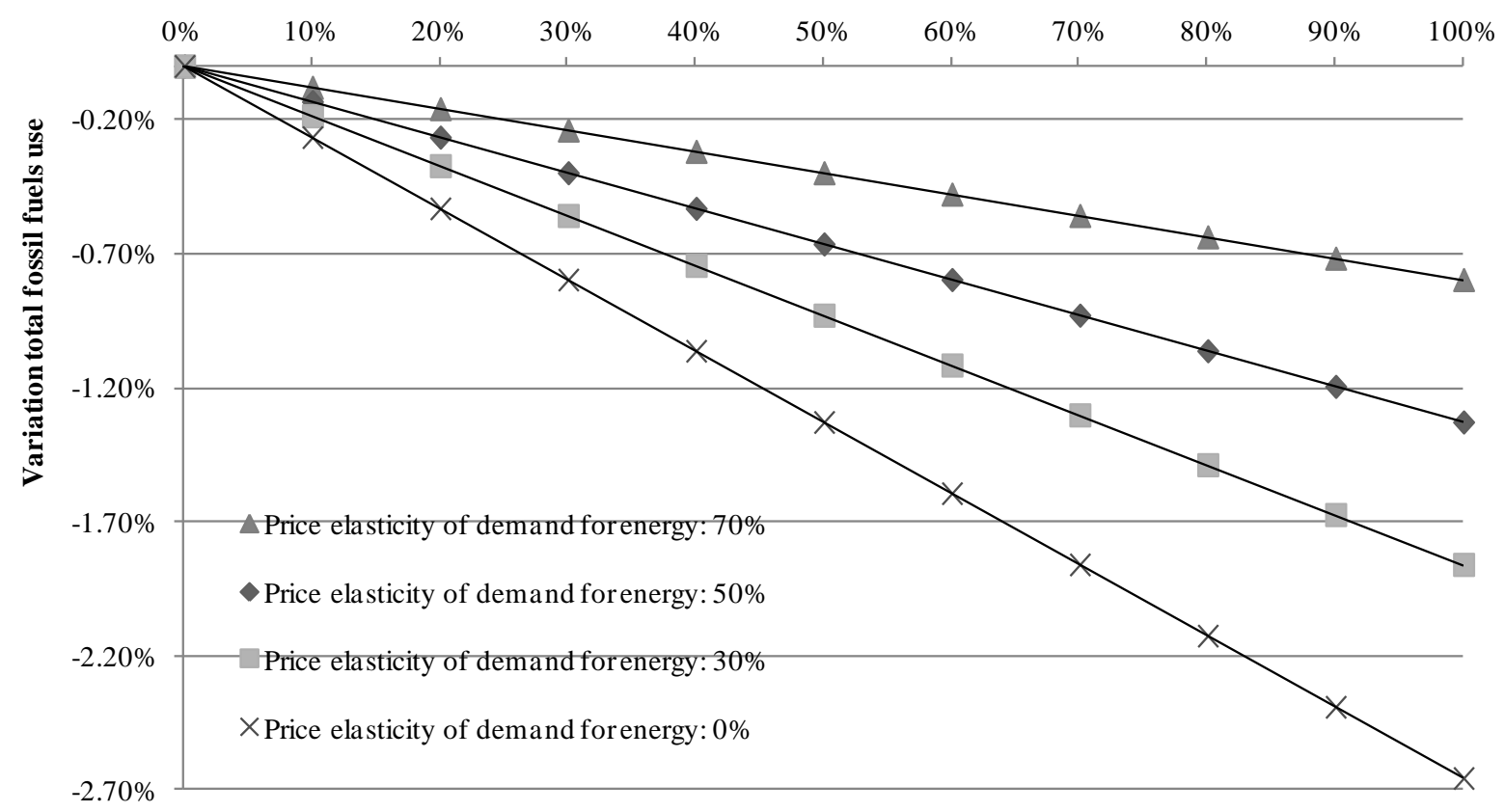

Figure 2 Fossil fuels variation after an energy efficiency improvement in households in Spain under different scenarios.

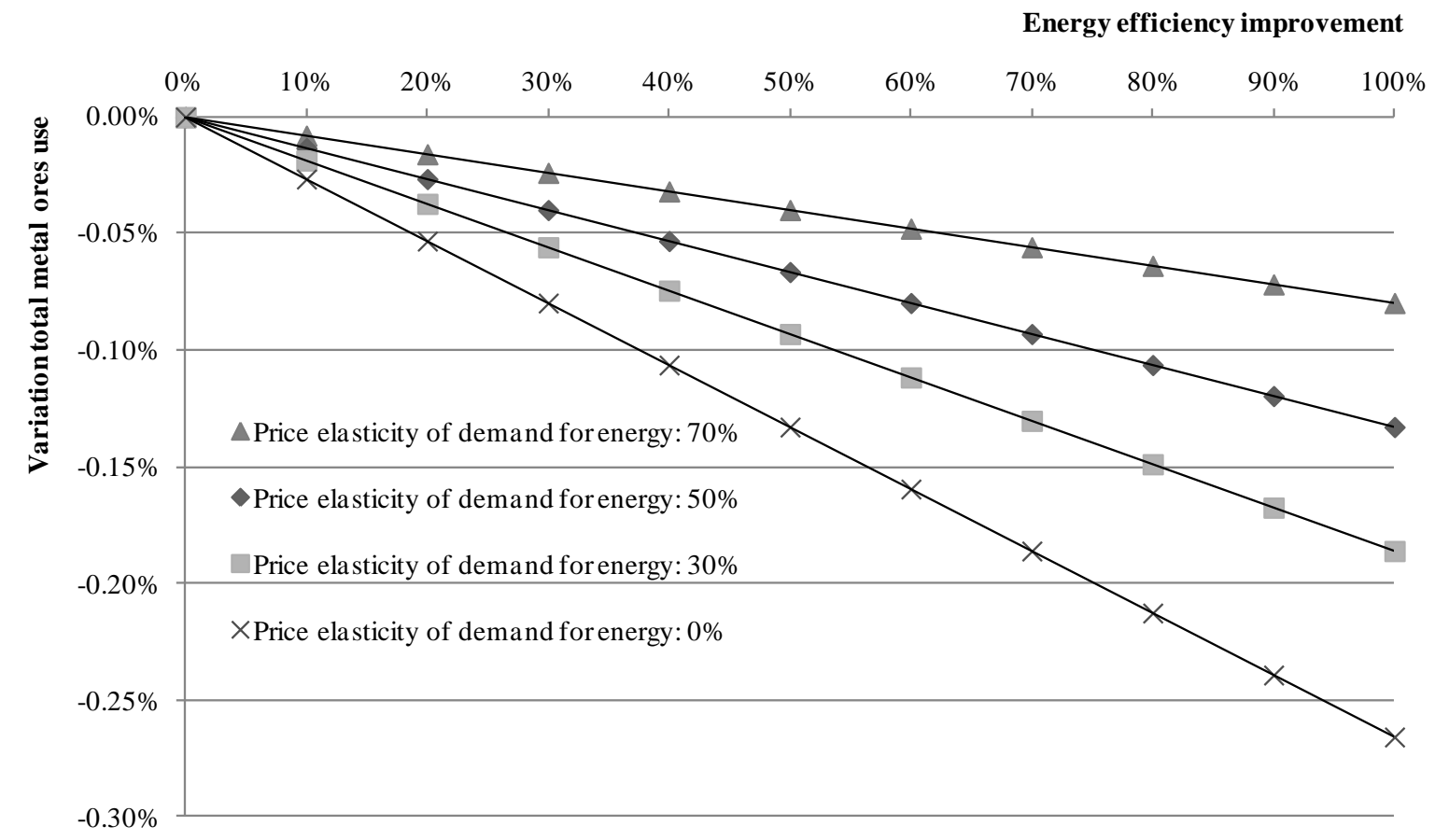

Figure 3 Metal ores variation after an energy efficiency improvement in households in Spain under different scenarios. 


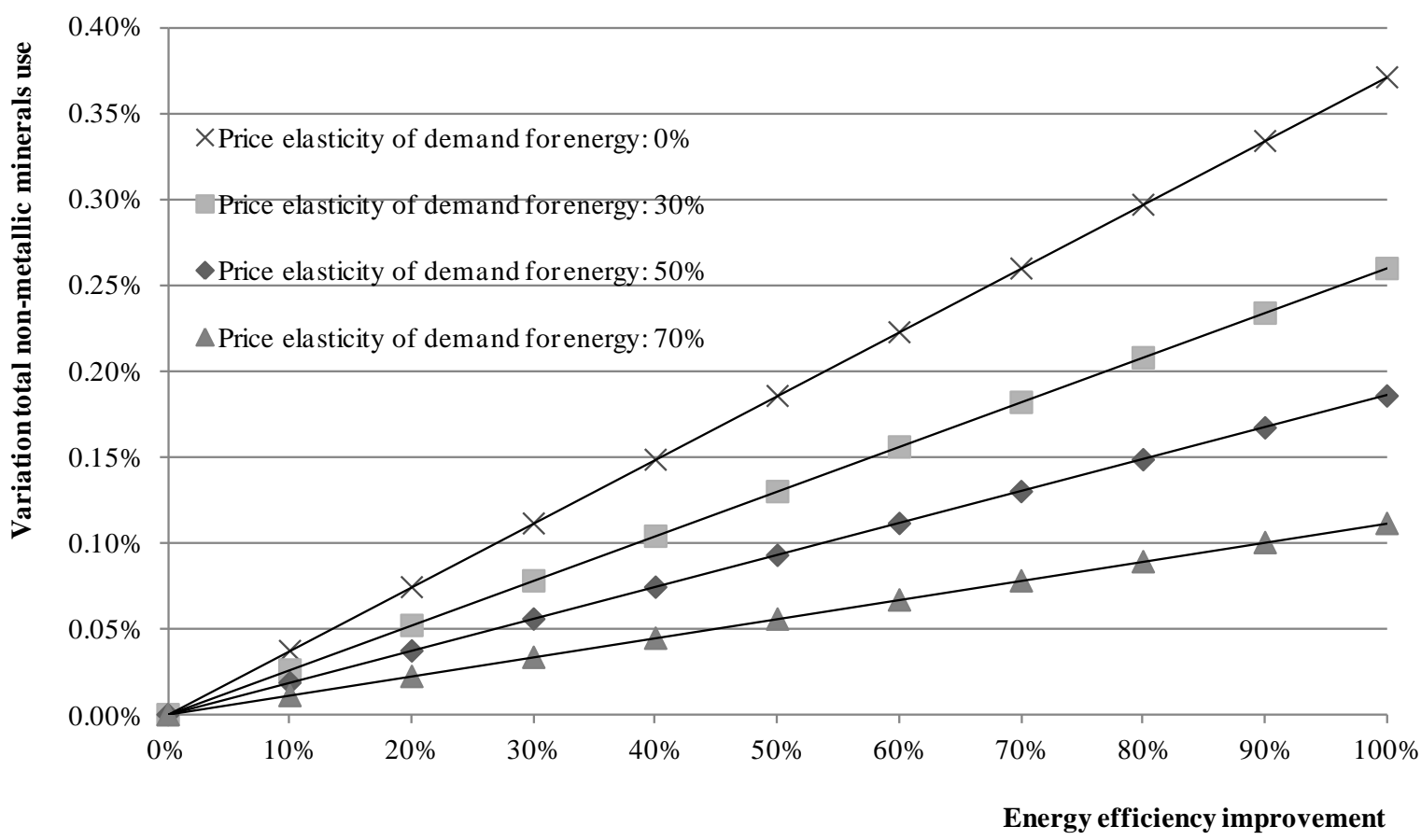

Figure 4 Non-metallic minerals variation after an energy efficiency improvement in households in Spain under different scenarios.

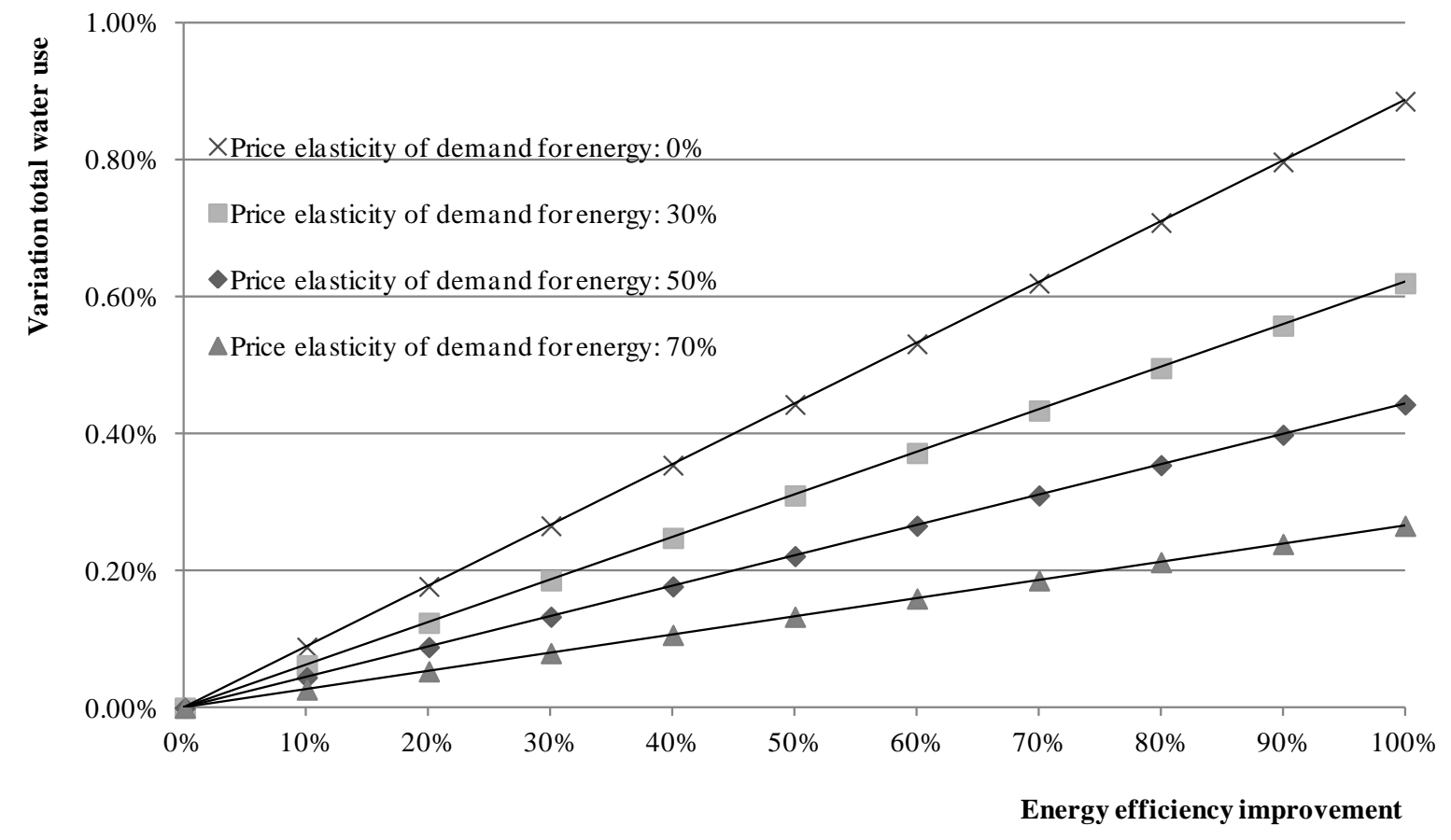

Figure 5 Water variation after an energy efficiency improvement in households in Spain under different scenarios.

Figures 1-5 show how, after different levels of energy efficiency improvements in households, there is a variation of the total (direct and indirect) use of different resources: energy, metal 
ores; and an increase of the consumption of non-metallic minerals and water. The size and direction of the variation depends in each case on the economic structure, the energy efficiency improvement, and the own price elasticity of the demand of energy. However, the economic structure and the resource consumption structure are the most determinant factors. Other economic structures with different resource intensities and economic relationships would lead to different results.

Table 1 shows the DICRE of the specific case of Spain for the different resources analysed, following the methodology described in section 3.

Table 1 Direct and indirect cross rebound effect for selected natural resources from energy efficiency improvements in Spanish households.

\begin{tabular}{lccccc}
\hline \multirow{2}{*}{ Resource } & \multicolumn{5}{c}{ Price elasticity of the demand for energy } \\
\cline { 2 - 6 } & $\mathbf{0}$ & $\mathbf{- 0 . 3}$ & $\mathbf{- 0 . 5}$ & $\mathbf{- 0 . 7}$ & $\mathbf{- 1}$ \\
\hline $\begin{array}{l}\text { Energy (Direct } \\
\text { indirect rebound effect) }\end{array}$ & $\mathbf{4 9 . 4 2 \%}$ & $\mathbf{6 4 . 6 0 \%}$ & $\mathbf{7 4 . 7 1 \%}$ & $\mathbf{8 4 . 8 3 \%}$ & $\mathbf{1 0 0 \%}$ \\
\hline Fossil fuels & $25.18 \%$ & $47.63 \%$ & $62.59 \%$ & $77.56 \%$ & $100 \%$ \\
\hline Metal ores & $77.53 \%$ & $84.27 \%$ & $88.77 \%$ & $93.26 \%$ & $100 \%$ \\
\hline Non-metallic minerals & $167.26 \%$ & $147.08 \%$ & $133.63 \%$ & $120.18 \%$ & $100 \%$ \\
\hline Water & $2,283.34 \%$ & $1,628.34 \%$ & $1,191.67 \%$ & $755.00 \%$ & $100 \%$ \\
\hline
\end{tabular}

There are strikingly different values of DICRE between energy efficiency and other natural resources analysed, depending on the economic structure composition, the natural resource analysed, and the price elasticity of the demand for energy. The results of the DICRE in terms of energy, which is what the research on the rebound effect typically assesses, and assuming a price elasticity between -0.3 and -0.5 (as the literature suggests for Spain [Freire-González, 2017]), are between $64.6 \%-74.7 \%$.

The DICRE for fossil fuels would be lower than the one for energy, concretely between $48 \%$ $63 \%$ (assuming the same elasticity range). This means that an energy efficiency improvement would only reduce approximately half of the expected reduction of fossil fuels. A similar case can be found regarding metal ores, but with even less final savings due to a high DICRE of between $84 \%-89 \%$. The DICRE results for non-metallic minerals and water use describe an increase of their overall use after an energy efficiency improvement in households. The results for water show a particularly high rebound effect, higher than $2,000 \%$ in the most extreme case, 
meaning that energy efficiency improvements in households trigger a notable net increase in the use of these resources. In these cases, we observe a special case of the Jevons Paradox (Jevons 1865), but applied to other resources. In other words, following energy efficiency improvements and its associated DICRE, we observe co-benefits in the form of net reductions in fossil fuels and metal ores, and trade-offs via net increases in non-metallic minerals and water use.

Our results are somewhat consistent with some of the related literature. Concretely, Thiesen et al. (2008), Font Vivanco et al. (2014) (2015), and Takase et al. (2005) found a wide range of rebound effect estimates when using various environmental indicators. In this sense, Font Vivanco (2016) argues that the consideration of the life cycle burdens in terms of multiple environmental indicators can cause such wide variations in the rebound magnitude, including an increased occurrence of backfire effects. A key reason is the asymmetry in the resource use intensity associated with the final demand categories: some resources such as energy are evenly used across economic sectors, while others such as water concentrate on a few sectors (e.g. agriculture) (Peters et al., 2016). Consequently, the reallocation of expenditure from resource non-intensive to resource intensive sectors can cause such variations via the indirect rebound effect. Moreover, Thomas and Azevedo (2013) analysed direct and indirect rebound effects from residential energy efficiency investments in terms of energy, $\mathrm{CO}_{2}, \mathrm{NO}_{\mathrm{x}}$, and $\mathrm{SO}_{2}$, and found moderate differences between these indicators. Our results may thus suggest that the consideration of broader environmental indicators, especially those not directly related to energy use, can introduce higher variability in the rebound magnitude from energy efficiency improvements.

\section{Conclusions}

As the rebound effect literature has demonstrated, energy efficiency improvements can be less effective as expected in reducing energy consumption due to the economic agents' behaviour. If we assume that an energy efficiency improvement increases the available income due to the reduction of energy costs, we find not only an increase of indirect use of energy, but also an additional variation of other resources' use. This research demonstrates that, expanding the indirect rebound framework to other resources and using input-output techniques, an energy efficiency improvement triggers relevant changes in the indirect consumption of other resources. 
Our findings suggest that conceiving rebound effects beyond energy indicators is key to assess the complete consequences of energy efficiency policies. Such consequences can be understood in terms of three effects: co-benefits, trade-offs and backfire. In this context, cobenefits and trade-offs take place when a reduction in energy use leads to an overall reduction or increase in another resource, respectively. A better understanding of these effects can be valuable to inform integrated environmental policies (e.g. joint energy and water efficiency policies) and increase the effectiveness of achieving environmental targets. These features resonate with the resource nexus and related frameworks (Andrews-Speed et al., 2014), and suggests synergistic research avenues, including finding optimal solutions between competing interests (Bizikova et al., 2013). Lastly, fears of backfire effects have been looming the academic and policy arenas since the early works of Stanley Jevons, yet limited evidence has supported their occurrence so far (Jenkins et al., 2011). Our findings, in line with other applications of the environmental rebound effect concept (Font Vivanco et al., 2016), suggest that the consideration of non-energy resources has important implications for the likelihood of such backfire effects. This has deep policy implications in the context of achieving critical sustainability goals, as rebound effects are sometimes downplayed (Gillingham et al., 2013).

Regarding the Spanish case, we observe that energy efficiency increases the use of some of the analysed resources and reduces the use of some others. There is no a general pattern. However, it is quite straightforward to track how different resources or materials are affected by using input-output or life cycle assessment techniques. More data on the use of resources linked to national accounts is needed to conduct deep and comprehensive empirical analyses of energy efficiency effects on resources use.

New metrics on efficiency improvements and global resources are needed to compute the total effect of productivity improvements and resources use. Further theoretical and empirical research is needed to improve this framework, and more data is needed in order to provide more empirical analyses for different countries and different resources, especially those ones that are critical for economies and for ecosystems, and are not renewable. Policy-makers should take into account the results of this study for the design and implementation of energy policies.

\section{References}


Atkinson, J., and N. Manning. 1995. A survey of international energy elasticities. Global warming and energy demand: 47-105.

Becker, G.S. 1965. A theory of the allocation of time. The Economic Journal LXXV(299): 493-517.

Berkhout, P.H., J.C. Muskens, and J.W. Velthuijsen. 2000. Defining the rebound effect. Energy Policy 28: 425-432.

Brons, M., P. Nijkamp, E. Pels, and P. Rietveld. 2008. A meta-analysis of the price elasticity of gasoline demand. A SUR approach. Energy Economics 30(5): 2105-2122.

Brookes, L.G. 1979. A low energy strategy for the UK, by G. Leach et al.: a review and reply. Atom 269: 3-8.

Chitnis, M., S. Sorrell, A. Druckman, S.K. Firth, and T. Jackson. 2014. Who rebounds most? Estimating direct and indirect rebound effects for different UK socioeconomic groups. Ecological Economics 106: 12-32.

Dimitropoulos, J., and S. Sorrell. 2006. The Rebound effect: Microeconomic Definitions, Extensions and Limitations. Proceedings of the 29th IAEE International Conference, Potsdam, Germany.

Druckman, A., M. Chitnis, S. Sorrell and T. Jackson (2011). "Missing carbon reductions? Exploring rebound and backfire effects in UK households" Energy Policy 39: 3572-3581.

Font Vivanco, D., W. McDowall, J. Freire-González, R. Kemp, and E. van der Voet. 2016. The foundations of the environmental rebound effect and its contribution towards a general framework. Ecological Economics 125: 60-69.

Freire-González, J. 2010. Empirical evidence of direct rebound effect in Catalonia. Energy Policy 38(5): 2309-2314.

Freire-González, J. 2011. Methods to empirically estimate direct and indirect rebound effect of energy-saving technological changes in households. Ecological Modelling 223(1): 32-40.

Freire-González, J. 2017. Evidence of direct and indirect rebound effect in households in EU27 countries. Energy Policy, 102, 270-276.

Freire-González, J., D. Font Vivanco, and I. Puig-Ventosa. 2017. Economic structure and energy savings from energy efficiency in households. Ecological Economics 131: 12-20.

Greening, L.A., D.L. Greene, and C. Difiglio. 2000. Energy efficiency and consumption - the rebound effect - a survey. Energy Policy 28: 389-401.

IEA (2015). Energy efficiency market report. OCDE Paris.

Jevons, W. S. (1865). The Coal Question. London: Macmillan and Co. 
Khazzoom, J.D. 1980. Economic implications of mandated efficiency standards for household appliances. Energy Journal 1, 21-39.

Leontief, W. 1941. The Structure of American Economy 1919-1939. New York, Oxford.

Miller, R.E., and P.D. Blair. 2009. Input-Output Analysis: Foundations and Extensions, 2nd ed. Cambridge, Cambridge University Press.

Saunders, H.D. 1992. The Khazzoom-Brookes Postulate \& neoclassical growth. The Energy Journal 13(4): 131-148.

Sorrell, S. 2007. The rebound effect: an assessment of the evidence for economy-wide energy savings from improved energy efficiency. UK Energy Research Centre.

Suganthi, L., and A.A. Samuel. 2012. Energy models for demand forecasting-A review. Renewable and sustainable energy reviews 16(2): 1223-1240.

Thomas, B.A., and I.L. Azevedo. 2013b. Estimating direct and indirect rebound effects for U.S. households with input-output analysis Part 1: Theoretical Framework. Ecological Economics 86, 199-210.

Thomas, B.A., and I.L. Azevedo. 2013a. Estimating direct and indirect rebound effects for U.S. households with input-output analysis Part 2: Simulation. Ecological Economics 86, 188-198. Tukker, A., A. de Koning, R. Wood, T. Hawkins, S. Lutter, J. Acosta, J.M. Rueda Cantuche, M. Bouwmeester, J. Oosterhaven, T. Drosdowski, and J. Kuenen. 2013. EXIOPOL development and illustrative analyses of a detailed global MR EE SUT/IOT. Economic Systems Research 25 (1): 50-70.

Wood, R., K. Stadler, T. Bulavskaya, S. Lutter, S. Giljum, A. de Koning, J. Kuenen, H. Schütz, J. Acosta-Fernández, A. Usubiaga, M. Simas, O. Ivanova, J. Weinzettel, J.H. Schmidt, S. Merciai, and A. Tukker (2015). Global sustainability accounting-developing EXIOBASE for multi-regional footprint analysis. Sustainability 7(1): 138-163.

\section{AFEGIR REFS A LLOC:}

Alfredsson, E.C., 2004. Green consumption - no solution for climate change. Energy 29, 513-524.

Andrews-Speed, P., Bleischwitz, R., Boersma, T., Johnson, C., Kemp, G., VanDeveer, S.D., 2014. Want, waste or war?: the global resource nexus and the struggle for land, energy, food, water and minerals. Routledge.

Bizikova, L., Roy, D., Swanson, D., Venema, H.D., McCandless, M., 2013. The water-energy-food security nexus: Towards a practical planning and decision-support framework for landscape investment and risk management. International Institute for Sustainable Development.

Chitnis, M., Sorrell, S., Druckman, A., Firth, S.K., Jackson, T., 2013. Turning lights into flights: Estimating direct and indirect rebound effects for UK households. Energy Policy 55, 234-250. 
Chitnis, M., Sorrell, S., Druckman, A., Firth, S.K., Jackson, T., 2014. Who rebounds most? Estimating direct and indirect rebound effects for different UK socioeconomic groups. Ecological Economics 106, 12-32.

Druckman, A., Chitnis, M., Sorrell, S., Jackson, T., 2011. Missing carbon reductions? Exploring rebound and backfire effects in UK households. Energy Policy 39, 3572-3581.

Font Vivanco, D., 2016. The rebound effect through industrial ecology's eyes: the case of transport eco-innovation. Institute of Environmental Sciences (CML), Faculty of Science, Leiden University.

Font Vivanco, D., Freire-González, J., Kemp, R., van der Voet, E., 2014. The Remarkable Environmental Rebound Effect of Electric Cars: A Microeconomic Approach. Environmental Science \& Technology 48, 12063-12072.

Font Vivanco, D., Kemp, R., van der Voet, E., 2015. The relativity of eco-innovation: environmental rebound effects from past transport innovations in Europe. Journal of Cleaner Production 101, 71-85. Font Vivanco, D., McDowall, W., Freire-González, J., Kemp, R., van der Voet, E., 2016. The foundations of the environmental rebound effect and its contribution towards a general framework. Ecological Economics 125, 60-69.

Font Vivanco, D., van der Voet, E., 2014. The rebound effect through industrial ecology's eyes: a review of LCA-based studies. The International Journal of Life Cycle Assessment 19, 1933-1947.

Gillingham, K., Kotchen, M.J., Rapson, D.S., Wagner, G., 2013. Energy policy: The rebound effect is overplayed. Nature 493, 475-476.

Goedkoop, M., Van Halen, C., te Riele, H., Rommens, P., 1999. Product Service Systems, Ecological and Economic Basics.

Greening, A., Greene, D.L., Difiglio, C., 2000. Energy efficiency and consumption - the rebound effecta survey. Energy Policy 28, 389-401.

Jenkins, J., Nordhaus, T., Shellenberger, M., 2011. Energy emergence: rebound and backfire as emergent phenomena. Breakthrough Institute.

Murray, C.K., 2013. What if consumers decided to all 'go green'? Environmental rebound effects from consumption decisions. Energy Policy 54, 240-256.

Peters, G.P., Andrew, R.M., Karstensen, J., 2016. Global environmental footprints: A guide to estimating, interpreting and using consumption-based accounts of resource use and environmental impacts. Nordic Council of Ministers.

Saunders, H.D., 2000. A view from the macro side: rebound, backfire, and Khazzoom-Brookes. Energy Policy 28, 439-449.

Sorrell, S., 2007. The rebound effect: an assessment of the evidence for economy-wide energy savings from improved energy efficiency. Project Report, in: Centre, U.E.R. (Ed.).

Takase, K., Kondo, Y., Washizu, A., 2005. An Analysis of Sustainable Consumption by the Waste InputOutput Model. Journal of Industrial Ecology 9, 201-219.

Thiesen, J., Christensen, T., Kristensen, T., Andersen, R., Brunoe, B., Gregersen, T., Thrane, M., Weidema, B., 2008. Rebound effects of price differences. The International Journal of Life Cycle Assessment 13, 104-114.

Thomas, B.A., Azevedo, I.s.L., 2013. Estimating direct and indirect rebound effects for U.S. households with input-output analysis. Part 2: Simulation, Ecological Economics

Sustainable Urbanisation: A resilient future, pp. 188-198.

Zhang, Y.-J., Liu, Z., Qin, C.-X., Tan, T.-D., 2017. The direct and indirect CO2 rebound effect for private cars in China. Energy Policy 100, 149-161. 